\title{
Lighting the way: photonics leaders II (PL2) optics and photonics teacher professional development
}

Pamela Gilchrist, Joyce Hilliard-Clark, Tuere Bowles, Eric Carpenter

Pamela Olivia Gilchrist, Joyce Hilliard-Clark, Tuere Bowles, Eric Carpenter, "Lighting the way: photonics leaders II (PL2) optics and photonics teacher professional development," Proc. SPIE 9289, 12th Education and Training in Optics and Photonics Conference, 928917 (17 July 2014); doi: $10.1117 / 12.2070383$

SPIE Event: 12th Education and Training in Optics and Photonics Conference, 2013, Porto, Portugal 


\title{
Lighting the Way: Photonics Leaders II (PL2) Optics and Photonics Teacher Professional Development
}

\author{
Pamela Olivia Gilchrist ${ }^{\mathrm{a}}$, Joyce Hilliard-Clark ${ }^{\mathrm{a}}$, Tuere Bowles ${ }^{\mathrm{b}}$, Eric Carpenter ${ }^{\mathrm{c}}$ \\ ${ }^{a}$ The Science House, North Carolina State University, 909 Capability Dr., Raleigh, NC USA 27695 \\ ${ }^{\mathrm{b}}$ Department. Of Leadership, Policy, and Adult Higher Education, North Carolina State University, \\ Box 7801, Raleigh, NC USA 27695 \\ ${ }^{c}$ Department. Of Psychology, North Carolina State University, Box 7650, Raleigh NC USA 27695
}

\begin{abstract}
A sample group of nineteen teachers completed the second phase of the Photonics Leaders II Optics and Photonics professional development program. Participants took a basic Physics content knowledge test that was designed by a Professor of Physics. The test was completed before the teachers participated in the program and at the end of the program to gather data for statistical inquiry. Statistical studies on pre-test and post-test data indicated significant gains in physics content knowledge over time, and that instructors teaching at the middle school level or only teaching one subject area scored significantly lower during the pretest. Reports from previous participants are summarized to disseminate the percentage of teachers who have incorporated at least one workshop activity and the kind of activity performed. The concerns and limitations reported by previous participants are reviewed as well.
\end{abstract}

Keywords: photonics, professional development

\section{INTRODUCTION}

One-third of the 23,000 United States high school physics teachers enter the field with degrees in physics or physics education ${ }^{1}$. The remaining two-thirds of physics teachers are unprepared to teach physics content to students. In response to this trend, the National Science Foundation and American Physical Society $21^{\text {st }}$ Century Campaign Committee supported the establishment of the Physics Teacher Education Coalition (PhysTEC) in 1999 to improve teacher education programs and prepare future physics teachers ${ }^{1}$. PhysTEC collaborative efforts with universities and other organizations have contributed significantly towards improving physics and physical science teachers' deep understanding of physics concepts and experience with research-based pedagogical approaches mainly on the secondary level. These programs have focused on developing teachers' understanding of classical mechanics concepts instead of an understanding of classical optics and modern optics content. An even smaller amount of content-focused professional development has been offered on the elementary and middle school level. For example, a physics-based study of elementary and middle school teacher education program indicated a gap in pre-service and in-service participants' knowledge of light ${ }^{2}$, thus indicating a need to provide more content-driven professional developments for novice and veteran teachers. Another study suggested that modifying curricula for improving optics instructions for high school and college students in teacher-training programs would improve the conceptual knowledge of educators ${ }^{3}$.

A recent National Academy of Science report indicated a need to improve the technical education of skilled workers in the field of optics and photonics considering its transformative advancements and impact on the nation's economy ${ }^{27}$. For this to effectively occur in the United States, this content must not only be employed on the higher education and government level, but also on the K-12 level to produce STEM workers in this field ${ }^{22,23,24,25,26,27}$.

Therefore, a need exists to prepare middle and high school teachers to teach optics and photonics concepts to students. Optics and photonics teacher workshops are critically essential, as state and national data has documented its dramatic impact in our society, lack of trained professionals entering the teaching profession, and the need to develop an

12th Education and Training in Optics and Photonics Conference, edited by

Manuel F. P. C. Martins Costa, Mourad Zghal, Proc. of SPIE Vol. 9289, 928917

(C) 2014 SPIE, OSA, IEEE, ICO·doi: 10.1117/12.2070383

Proc. of SPIE Vol. 9289 928917-1 
education infrastructure that supports the vibrant future of optics and photonics as an essential enabler of technologies in our nation $22,23,24,25,26,27$.

One effort to create content-driven professional development occurs at The Science House, which is the primary leading outreach program of the College of Physical and Mathematical Sciences at North Carolina State University in Raleigh, North Carolina. The program is a national model for the interaction of university department scientists, K-12 students, and teachers across the state of North Carolina and beyond. The program's mission is to motivate and prepare K-12 students to study and work in STEM fields and to educate and empower teachers to effectively integrate innovative STEM content, research and technologies through innovative programs. Members of The Science House staff created the hybrid Photonics Leaders II (PL2) Optics and Photonics teacher professional development program to introduce teachers to optics and photonics content for classroom implementation with students in their respective schools

In the program, we used real world connections and scientific justifications to explain the concepts behind technologies (i.e., computers, cell phones, lasers, iPods, fiber optics) that will increase teachers' and ultimately students' understanding of the importance and relevancy of physics. The PL2 program provided ongoing support, research-based practices, educational resources, and a rich experiential learning environment to foster teacher reflection, active participation, classroom implementation and discourse.

The PL2 Optics and Photonics teacher professional development's logic model is aligned with Guskey's ${ }^{4}$ change theory that posits that experiential staff development and classroom implementation will produce a change in teachers' classroom practices, beliefs, and attitudes. It is through motivation and learning that teachers change their ability to engage students in learning science content in an inquiry and authentic manner. Guskey's staff development model is used to guide programs such as PL2 that change teachers' classroom practices, beliefs, attitudes and student learning outcomes. His research has shown that teachers' commitment to change and their use of new instructional strategies strengthen after successful implementation and a measurable impact is shown with student learning outcomes ${ }^{4}$.

\subsection{Problem}

An educator's perception about his or her understanding of science content (especially physics), availability of resources, and pedagogical support influences their freedom to integrate the content into their classroom with confidence. The PL2 Optics and Photonics teacher professional development program design addresses the problem of how to integrate scientific content, transformative instructional strategies, and technology resources to enhance and support teachers' efforts to improve students' scientific knowledge, skills and attitudes.

The program employs a hybrid (an integration of face-to-face and online-synchronous and asynchronous sessions) approach that incorporates the following:

1) Immersion in physics content via inquiry;

2) Exploration of real-world applications in the laboratory and via industry tours;

3) Exposure to online learning communities (Elluminate Live) and content management systems (Moodle);

4) Classroom implementation and dissemination of learned physics content and activities;

5) Online collaboration and reflection of teaching experience; and

6) Evaluation of the impact on the individual teacher, students and/or colleagues.

The professional development provides teachers with multiple entry points to engage learners in an understanding of light, optics, and photonics concepts. This paper will focus on Phase I of the study, which reports a sampling of preliminary implementation findings of middle and high school teachers during their actual participation in the program in 2010. Phase II of the study is currently underway; the researchers will provide post-implementation findings in a subsequent publication. 


\subsection{Literature Review}

Multiple sources have noted concern for the level of achievement reached by American students in STEM courses or the preparation of these students for competitive STEM related professions, $5,7,8$. Previous studies that examined improving interest or performance in STEM areas have focused on students alone ${ }^{9}$, on child/parent dyads ${ }^{10}$, or teachers themselves ${ }^{11}$. Research that focuses on students has found that the courses a student completes may predict their choosing STEM areas as a degree path in postsecondary education. Additionally, studies that focus on instructors have suggested that teachers with more learning resources in addition to a background in a content area will be more successful in communicating their knowledge to students ${ }^{6}$. However, the National Science Foundation (NSF) has noted that previous efforts to examine the effectiveness of professional development opportunities has been hindered due to an absence of tools available for determining teacher subject knowledge ${ }^{6}$.

Other areas of research about teachers' professional development include multicultural understanding, individuated instruction, and differentiated instruction ${ }^{12,13,14,15,16,17}$. These studies have shown that school classrooms are becoming increasingly diverse although teachers may not feel prepared to teach in diverse classrooms ${ }^{15,16}$. Indeed, the children in a classroom may vary in terms of demographic characteristics, presence or type of learning disability, cultural background, level of preparedness in a subject, interest in classroom material, and many other variables ${ }^{14,17}$. In addition to these sources of student variance, some researchers and educators have placed increased focus on teaching students how to think over what to think ${ }^{18,19}$.

As teachers adopt approaches that move away from teaching all students the same static facts, they will likely encounter more variety in the types of questions they face from students. Researchers who examine multicultural awareness, individuated instruction, and differentiated instruction have been able to demonstrate that the use of face-to-face teacher workshops combined online support (hybrid instruction) can raise a teacher's knowledge concerning diverse populations; can result in increased instructor confidence ratings related to teaching diverse populations; and enhances skills in teaching such populations ${ }^{15,16}$. Additionally, research suggests that the use of multi-age classrooms where students are not grouped according to their chronological ages and courses wherein students are unaware of their grades can result in higher test scores. The use of interest-based study, allowing students some degree of freedom in the topics they learn about, is recommended as well ${ }^{17}$.

The research findings and recommendations concerning teacher professional development mentioned above influenced the PL2 program in many ways during its creation. While participants in the PL2 teacher workshop completed multiple assignments such as knowledge tests and personal reflections, participants were never made aware of any grades they received on these assignments. Additionally, all instructors were placed in the same classroom regardless of age or level of expertise in teaching. Teacher participants were introduced to multiple hands-on experiments meant to teach students about physics and photonics topics while creating interest in the material. The material presented to participants was designed with a diverse classroom in mind, thereby allowing instructors to spend more or less time on a topic as well as to alter the level of support provided to a class during actual classroom instruction. Additionally, participating teachers learned how to help students design experiments to test hypotheses personally relevant to individual students.

Feedback and suggestions were provided from The Science House Staff, PL2 Project Advisory Committee, and public school teachers during the design of the PL2 program curriculum at multiple points, resulting in an iterative, participatory design type of formative evaluation ${ }^{20}$. The final team tasked with the evaluation of the PL2 program consisted of individuals internal and external to The Science House, ensuring a full understanding of the program's elements while reducing the risk of bias when interpreting findings. Additionally, team members were assigned components of the PL2 program to evaluate based on their differing areas of expertise, including one external evaluator with a considerable evaluation background. 


\section{METHOD}

Both qualitative and quantitative data were collected in a pre-test/post-test fashion to allow for statistical testing of content knowledge gains $\mathrm{s}^{20,21}$. This article reports on a subset of quantitative data from a larger ongoing longitudinal program. This current paper presents findings from a physics knowledge test administered to participating Cohort II teachers during a pretest and posttest as well as analyzes information from previous participants about the activities they have performed in their classrooms after finishing the program.

\subsection{Participants}

The second cohort of the Photonics Leaders II program contained a total of 19 educators. Overall $68.4 \%(\mathrm{n}=13)$ of participants were female and $31.6 \%(n=6)$ were male. Teachers represented three levels of schooling with $47.4 \%(n=9)$ of teachers working at the middle school level; $42.1 \%(\mathrm{n}=8)$ working at the high school level; and $10.5 \%(\mathrm{n}=2)$ working at the community college level. All schools represented were public schools in North Carolina, representing a variety of school systems. Table 1 examines the demographic breakdown of participating Cohort II teachers. A total of 53 teacher participants were eligible to return summaries of the activities they have used in their classrooms from the Photonics Leaders II program; however, only $21(40 \%)$ of teachers did so.

\subsection{Procedures}

The PL2 teacher workshop is a hybrid experiential program for middle, high school and community college teachers. The 44-contact-hour program consists of 28 contact hours with an intensive face-to-face experience (three days) and an online follow-up experience (two days). The workshop is offered at The Science House on North Carolina State University's Centennial Campus. Middle or high school teachers in grades 6-12 who teach Physics concepts and/or workforce skills from underserved rural areas and/or who possess a willingness to work with diverse learners are the target recruitment audience. Participants register for the workshop via the program website and complete a survey outlining their subject areas taught, attitude towards teaching diverse students, and willingness to disseminate work in their schools or within the Photonics Leaders II student component.

The program is delivered through the following five phases: 1) inquiry, 2) internship, 3) technology 4) dissemination, and 5) online follow-up. Each participant is required to participate in all phases to receive the program stipend of $\$ 500$. The five-day hybrid training occurs annually for three years and is reviewed annually with formative and summative evaluation methods to measure the impact of the program and the needs of the target population. The online component is used as a community of exchange and introduces participants to problem-based learning curriculum materials for classroom implementation. The workshop objectives are as follows:

1. To introduce and model instructional strategies on Photonics, emerging STEM fields, careers, and workforce demands of the global society for middle school and high school educators.

2. To enhance teachers' skills, knowledge and behaviors towards teaching physics to all students, especially underrepresented minority students (URM).

3. To provide avenues for professional development through practical experience in formal and informal educational settings.

After completing the face-to-face and online portions of the program, teachers are required to submit progress reports on any activities from the program they later use in their classroom. Teachers are also encouraged to share any novel activities they created in part because of the program. A standard form was made available to all teachers for reporting on their activities, although submissions were not rejected if this form was not used.

\subsection{Instrumentation}

The knowledge test used in this study consisted of eight multiple-choice and open-ended items. Questions covered teachers' knowledge about a variety of physics and photonics subjects such as the speed of light in different mediums 
and explaining how to build a circuit. A professor of Physics with an expertise in Experimental Nuclear Physics created the assessment.

The implementation report was created by Photonics Leaders II staff to ensure participants reported which activities they performed, how each activity was worked into the teacher curriculum, how materials and group dynamics were handled, what individuals were to learn during the activity, and what recommendations participants had for the program staff after reflecting on the activities implemented.

\section{RESULTS}

Using a dependent samples t-test, analysis of teachers' knowledge scores from pre-test and post-test administration revealed that post-test scores $(M=23.24, S E=0.53)$ were significantly greater than pre-test scores $(M=19.41, S E=.79$, $t(16)=-4.31, p<.05, r=.73)$.

Analysis of the influence of a teacher's school setting on pre-test and post-test scores was examined using an independent samples $t$-test. On average, teachers in a high school or community college setting $(M=20.60, S E=1.18)$ scored significantly higher on the pre-test than teachers in a middle school setting $(M=17.0, S E=0.65, t(17)=-2.6, p<.05$, $r=.53)$.

The influence of the number of subject areas taught by a teacher on pre-test and post-test scores was examined using an independent samples $t$-test. On average, teachers who taught more than one subject area $(M=21.00, S E=1.27) \mathrm{scored}$ significantly higher on the pre-test than individuals only teaching one subject area $(M=17.67, S E=.865, t(17)=-2.24$, $p<.05, r=.01)$.

Out of the total 53 teachers that participated across all three cohorts of the Photonics Leaders II program, 21 returned an Implementation Report (40\%). From this sample of 21, 18 (86\%) teachers performed at least one hands-on activity. One teacher $(5 \%)$ performed both hands-on and online activities with students, including conducting an experiment with a distributed team consisting of another class of students in Japan. In total, 19 out of the 21 (90\%) who returned Implementation Reports indicated at least one activity had been performed with other teachers or students.

A total of 12 reports $(57 \%)$ voiced recommendations for the program staff. The most common recommendation was to give teachers more time and background on the activities from the program ( 5 out of 12: 42\%). Teachers requested more time to practice the activities, time to determine how to adapt the tasks for the age of their students, and more information about the expected results of the activities performed. Indeed, some teachers reported being unsure whether the results they experienced with their students were "normal." Teachers also requested assistance with obtaining the raw materials to perform the activities (3 out of 12:25\%). At least one teacher reported that a lack of funds required demonstrating to students rather than engaging students with hands-on activities. Two teachers requested that the activities presented in the program be more tailored by age group ( 2 out of $12: 17 \%)$. Another possibility mentioned by these teachers was to separate participants according to the age groups they taught in school to allow the groups to tailor the activities together; lastly, teachers requested that more content on pedagogy or virtual labs be included in the program (one teacher for each category: $8 \%$ each).

\section{DISCUSSION AND CONCLUSION}

Results of the dependent $t$-test on teacher pre-test and post-test scores demonstrate that significant gains in knowledge were realized in the time between test administrations. This suggests that the teacher professional development aspect of the Photonics Leaders II program is meeting its goal of increasing teachers' knowledge about physics and photonics content.

Findings concerning a teacher's job setting suggest that there are significant differences in the level of material teachers are exposed to in a professional setting, when preparing to become a teacher, or both. Given that the post-test results 
were not significantly different based on a teacher's school setting, the findings conclude the PL2 program contributed to equalizing the content knowledge of the three groups.

Results of the independent $t$-test on teacher pre-test and post-test scores based on the number of subject areas taught by a participant indicated significantly higher pre-test scores when individuals taught more than one subject. This suggests that the preparation for teaching multiple areas, on the job experience teaching multiple areas, or a combination of initial preparation and job experience is significantly different from instructors who only teach one area. Teaching multiple areas may result in more exposure to physics and photonics concepts as well as provide a more thorough knowledge base for teachers to use when inferring information about unfamiliar concepts. The lack of significant differences between knowledge scores based on the number of subject areas taught by a participant at the post-test time point suggests that the PL2 program contributed to equalizing the content knowledge of all participants. Future studies should examine differences in knowledge test scores based on the specific subject(s) taught.

Overall, results of the statistical analysis indicate that the PL2 program was a factor in the overall increased knowledge test scores for cohort II and in the reduction in knowledge test score differences between the different groups of participants. Additionally, in order to ensure greater increases in knowledge scores, future cohorts for the PL2 program or others like it could put a greater emphasis on recruiting middle school teachers or instructors who only teach a single subject area.

Results from the returned implementation reports were informative and will surely improve the effectiveness of the program in future iterations. That almost one-half of participants requested more time to experience the activities and their expected outcomes suggests the program may be providing too much content for the participants to become familiar with. This lack of familiarity may negatively influence teachers when they determine whether to include any of the program activities in their classrooms. Additionally, teachers may need to be taught that abnormal experimental outcomes are acceptable. Indeed, teachers may be encouraged to treat abnormal results as opportunities for further exploration with students. By refusing to treat abnormal results as wrong answers and instead using them as an introduction to scientific inquiry, teachers would be able to emphasize one of the most fundamental aspects of being a scientist to their students.

As $25 \%$ of the recommendations returned voiced concern with being able to gather the raw materials needed for the activities, future teacher professional development activities should consider giving funds or kits with all of the materials needed to run an activity with a teachers' students. Future programs should also consider incorporating reusable items into the activities to prevent the need for replacing materials each time an activity is planned.

This study was not without limitations. All participants received the same curriculum presented in the same fashion, and no control group was established for comparison. To ensure that the PL2 program is responsible for the increased knowledge test scores, future studies should compare different methods of instructional delivery, incorporate a control group for pre- and post-testing, or compare multiple cohorts from the PL2 program to one another. Additionally, while increases in curriculum knowledge were demonstrated over time, the post-test was delivered shortly after completion of the program. Follow-up testing should be conducted to determine if the knowledge gains decay over time. In addition to research on content knowledge, future studies should also examine whether participants incorporate PL2 content into their teaching or how to support teachers in incorporating the physics and photonics content. While cohort II was examined for test score differences based on job setting and number of subjects taught, no data was available for analysis on participant age or years of professional experience. Future studies should incorporate these variables into their data collection methods.

Multiple teachers in cohort II reported being unaware of the stipend associated with the PL2 program. Future studies should examine the influence of incentives or motivation on teacher learning and effectiveness, while future iterations of the PL2 program should put increased effort into making potential participants aware of all elements of the opportunity. Also, while there was considerable variability inside this sample, all participants indicated teaching some form of science or engineering; this suggests that the findings reported here may not translate to instructors without an equivalent background. Concerning results from the implementation reports, future programs should put greater effort into ensuring 
participants return the classroom implementation reports. It is unknown whether participants who failed to return a report performed program activities with their students. If teachers who failed to return reports did perform activities with students they may have faced unique challenges that were not documented by program staff. If teachers who failed to return reports did not perform activities with students, future studies could attempt to elicit why the teachers failed to do so in an attempt to overcome these obstacles in the future.

The National Science Foundation Innovative Technology Experiences for Students and Teachers under the division of Research on Learning in Formal and Informal Settings fully funded the Photonics Leaders II Program Award \#0833615.

Table 1

Cohort 2 Demographics

Characteristic $\quad \mathrm{n} \quad \%$

$\begin{array}{lcc}\text { Male } & 6 & 31.6 \\ \text { Female } & 13 & 68.4 \\ \text { Middle school } & 9 & 47.4 \\ \text { High school } & 8 & 42.1 \\ \text { Community college } & 2 & 10.5\end{array}$

\section{References}

[1] Hodapp, T., Hehn, J., \& Hein, W. (2009). Preparing high-school physics teachers. Physics Today, February, 40-45.

[2] Galili, I., \& Hazan, A. (2000). Learners' knowledge in optics: Interpretation, structure and analysis. International Journal of Science Education, 22(1), 58-88.

[3] Krall, R. M., Christopher, J. E., and Atwood, R. K. (2009). Comparison of central appalachian in-service elementary and middle school teachers' understanding of selected light and force and motion concepts. Science Educator, $18(1), 1-15$.

[4] Guskey, T. R. (1986). Staff development and the process of teacher change. Educational Researcher, 15(5), 5-12.

[5] Clewell, B. C., \& Campbell, P. B. (2002). Taking Stock: Where We've Been, Where We Are, Where We're Going. Journal of Women and Minorities in Science and Engineering, 8, 255-284.

[6] Committee on Science and Technology. (2008). STEM education before high school: Shaping our future science, technology, engineering, and math leaders of tomorrow by inspiring our children today (Serial No. 110-101). Washington, DC: U. S. Government Printing Office.

[7] Hoare C. (2009). Models of adult development in Bronfenbrenner's bioecological theory and Erikson's biopsychosocial life stage theory: Moving to a more complete three-model view. In M. C. Smith \& N. DeFrates-Densch (Eds.), Handbook of research on adult learning and development (pp.68-102). New York, NY: Taylor and Francis.

[8] Walsh, B. (2010, July 5). The electrifying Edison. Time, 176(1), 40-43. 
[9] Klahr, D., Triona, L. M., \& Williams, C. (2007). Hands on what? The relative effectiveness of physical versus virtual materials in an engineering design project by middle school children. Journal of Research in Science Teaching, 44(1), 183-203.

[10] Bowles, T., Grant, C., Martin, P., \& Carpenter, E. (in press). ADVANCE-ENG girls to women: An innovative engineering faculty-student mentoring summit for underrepresented minority (URM) girls and their mothers. 2010 ASEE Annual Conference and Exposition.

[11] Grant, C., Decuir-Gunby, J., \& Smith, B. (in press). Advance peer mentoring summits for underrepresented minority women engineering faculty. 2010 ASEE Annual Conference and Exposition.

[12] Baglieri, S., \& Knopf, J. H. (2004). Normalizing difference in inclusive teaching. Journal of Learning Disabilities, $37(6), 525-529$

[13] Han, H. S., \& Thomas, M. S. (2010). No child misunderstood: Enhancing early childhood teachers' multicultural responsiveness to the social competence of diverse children. Early Childhood Education Journal, 37, 469-476.

[14] Landrum, T. J., \& McDuffie, K. A. (2010). Learning styles in the age of differentiated instruction. Exceptionality, $18,6-17$.

[15] Maude, S. P., Catlett, C., Moore, S., Sànchez, S., Thorp, E. K., Corso, R. (2010). Infusing diversity constructs in preservice teacher preparation: The impact of a systematic faculty development strategy. Infants \& Young Children, 23(2), 103-121.

[16] Thomas, S., \& Kearney, J. (2008). Teachers working in culturally diverse classrooms: Implications for the development of professional standards and for teacher education. Asia-Pacific Journal of Teacher Education, 36(2), 105-120.

[17] Tomlinson, C. A., Brighton, C., Hertberg, H., Callahan, C. M., Moon, T. R., Brimijoin, K., Conover, L. A., \& Reynolds, T. (2003). Differentiating instruction in response to student readiness, interest, and learning profile in academically diverse classrooms: A review of literature. Journal for the Education of the the Gifted, 27(2), 119-145.

[18] Tanner, D., \& Tanner, L. (2007). Changing conceptions of curriculum. In D. Tanner \& L. Tanner (Eds.), Curriculum development: Theory into practice (pp. 98-123). Upper Saddle River, NJ: Pearson Education, Inc.

[19] Wardekker, W. (2004). Curriculum as vision. In J. Terwel \& D. Walker (Eds.), Curriculum as a shaping force: Toward a principled approach in curriculum theory and practice (pp. 1-15). Hauppauge, NY: Nova Science Publishers, Inc.

[20] Weiss, I. R. (1999). Evaluating science and mathematics professional development programs. Chapel Hill, N. C.: Horizon Research.

[21] Horizon Research and Westat, Inc. (2001). Revised handbook for studying the effects of the LSC on students. Retrieved June 15, 2010, from http://www.horizon-research.com/reports/2001/1schandbook.php

[22] Hilliard-Clark, J. \& Gilchrist, P. (2010). Imhotep Academy: photonics pre-college program model (3PM) ITEST Afterschool Convening, St. Paul, Minnesota. Retrieved from http://afterschoolconvening.itestlrc.edc.org/node/12

[23]Gilchrist, P. Hilliard-Clark, \& Bowles, T. (2010). Optics professional development in north carolina. SPIE Conference, San Diego, CA. Retrieved from $\quad$ http://spie.org/x648.html?product id=861057.

[24] Gilchrist, P., Hilliard-Clark, J. Conover, \& B. Dedugd, C. (2010). Piloting photonics curriculum in north carolina SPIE 2010. Retrieved from http://spie.org/x648.html?product id=861092.

[25] Hilliard-Clark, Gilchrist, P. \& Allgood, Sherri. (2009). Case study findings of problem based learning curriculum, International Society for Optics and Photonics (SPIE) Conference Presentation. San Diego, California, August 2009. Retrieved from http://spie.org/x648.html?product id=828689

[26] Hilliard-Clark, J \& Gilchrist, P. (2007). Photonics xplorers and leaders: Challenging diverse students in a flat world for emerging careers. Education and Training In Optics \& Photonics Conference, Ottawa, Canada. ETOP Proceeding Retrieved from http://spie.org/etop/2007/ETOP2007_Proceedings.pdf

[27] National Academy of Science (2012). Optics and photonics: essential enablers of our society. Retrieved from http://www.nap.edu/catalog.php?record_id=13491 